\title{
EL DERECHO COMO CIENCIA HERMENÉUTICA: LA DI- MENSIÓN JURÍDICA DE LA ACCIÓN HUMANA
}

\section{LAW AS A HERMENEUTIC SCIENCE: THE JURIDICAL DIMENSION OF HUMAN AGENCY}

\author{
Ángel Cubo MaYo \\ Inspección de Trabajo de Cataluña \\ Universidad Nacional de Educación a Distancia
}

Recibido: 14/04/2019 Aceptado: 18/09/2019

\section{RESUMEN}

Charles Taylor considera las ciencias humanas como ciencias hermenéuticas. Ciencias hermenéuticas serían aquellas que se ocupan del significado de textos, de acciones, de signos y de otros "portadores de significado", creados por los seres humanos para otros seres humanos. Así, el derecho entraría en el ámbito de las ciencias hermenéuticas. Sin embargo, una interpretación del Derecho no puede limitarse a lo textual. El Derecho tiene una doble agenda, por un lado, su objeto es a acción humana y su contexto social y, por otro, lo textual-normativo, en perpetua remisión y confrontación. La hermenéutica jurídica tradicional, entendida como interpretación de los enunciados jurídicos o textos, se equivoca al reducir lo jurídico a lo textual-regulador. Partiendo de esta premisa proponemos una hermenéutica que no olvide la relación dinámica entre acción humana y norma. Nos inspiramos en los trabajos de Viola y Zaccaria, Richard Rorty, Kauffman y Ricoeur. Desde esta perspectiva estudiaremos la posición hermenéutica de los tres grandes intérpretes del derecho: el legislador, el ciudadano y el aplicador (juez o funcionario) sin perder de vista que el derecho, como ciencia hermenéutica tiene como fin dar sentido y significado a la acción humana. 
Palabras clave: Hermenéutica, ciencias sociales, Derecho, acción humana, interpretación.

\section{ABSTRACT}

Charles Taylor considers human sciences as hermeneutic sciences. Hermeneutic sciences are those related to meaning of texts, actions, signs and others carriers of meaning, produced by the human beings for other human beings. Therefore, Law should come under the scope of hermeneutic sciences. However, the interpretation of law cannot be restricted to the understanding of the textual aspect. Law has a double agenda: on one hand, its object is human agency and its context as « the social factor " and, on the other hand, it focuses on the textual-regulative aspect, both of these objects in a relationship of mutual referral and confrontation. So, traditional legal interpretation is wrong when it reduces the comprehension of law to the understanding of the written rules. With this assumption, we propose a hermeneutic that doesn't dismiss the dynamic relationship of meaning between the human action and the rules. We draw our inspiration from the Viola \& Zaccaria, Richard Rorty, Kauffmann and Ricoeur works. From that perspective, we will turn on the hermeneutic view of the three great interpreters of law: legislator, citizens, as recipients of the normative rules, and the applicators of law (judges or civil servants) considering that law, as hermeneutic science, has the mission of giving sense and meaning to the human action.

Keywords: Hermeneutics, social sciences, Law, human agency, interpretation.

Sumario: 1. ¿Qué es la hermenéutica? 2. Ciencias humanas y significado. 3. El derecho como ciencia hermenéutica. 4. La hermenéutica jurídica. 5. Derecho y acción. 6. El punto de vista externo y el punto de vista interno. 7. Los intérpretes del derecho: 7.1. El legislador; 7.2. El ciudadano como intérprete principal del derecho; 7.3. El aplicador del derecho como intérprete del derecho.

\section{1. ¿QUÉ ES LA HERMENÉUTICA?}

Suele considerarse la hermenéutica general o filosófica como la filosofía de la interpretación. Si el racionalismo es la "filosofía de la razón" y el idealismo la "filosofía de la idea" la hermenéutica tendría como objeto 
de estudio de "la interpretación". Pero, a diferencia del racionalismo o del idealismo, la hermenéutica no se refiere a un objeto de estudio en particular: se interpreta aquello cuyo significado no está claro. Como señala Jean Grondin, las ideas de Gadamer, Ricœur y sus herederos apelan a menudo a la tradición más antigua de la hermenéutica, cuando ésta no designaba todavía una filosofía universal de la interpretación, sino sólo el arte de interpretar correctamente los textos ${ }^{1}$. Sin embargo, la hermenéutica contemporánea responde a inquietudes filosóficas de largo alcance. Aparece como respuesta a una teoría del conocimiento que establecía como único fundamento válido los "datos brutos" obtenidos después de una verificación a través del método científico propio de las ciencias naturales. Nietzsche, Husserl y, sobre todo, Heidegger pusieron de relieve que los seres humanos confieren significado a las cosas antes de que cualquier acercamiento científico analice su composición, estructura física o tendencias. La relación de conocimiento entre sujeto conocedor y objeto conocido está basada en premisas erróneas: el comportamiento teórico-cognoscitivo no puede dar cuenta del modo inicial de relacionarnos con el mundo. En palabras de Heidegger: "ni el conocimiento crea ab initio un commercium del sujeto con un mundo, ni este commercium surge de una acción del mundo sobre un sujeto”2.

Sin entrar en el desarrollo de la hermenéutica filosófica por cada uno de los autores que han desarrollado esta disciplina, la perspectiva hermenéutica señala a las ciencias humanas como ciencias del significado. Como afirma Taylor, interpretar es hacer comprensible el objeto estudiado y darle un cierto sentido y califica las ciencias humanas como ciencias hermenéuticas. Afirma que, para que una ciencia pueda llamarse hermenéutica, debe reunir los siguientes requisitos:

1 Jean Grondin, ¿QQué es la hermenéutica? (Barcelona: Herder Editorial, 2008), 16.

2 Martin Heidegger, Ser y tiempo, trad., prólogo y notas de Jorge Eduardo Rivera C. (Santiago de Chile: Editorial Universitaria, 1997), § 13. Ejemplificación del estar-en por medio de un modo fundado. El conocimiento del mundo. 
a) Debe tener un objeto o área de objetos sobre los cuales podamos hablar en términos de coherencia o incoherencia, de sentido o de falta de sentido

b) Tenemos que ser capaces de hacer una distinción, aunque sea relativa, entre ese sentido o esa coherencia y su encarnación en algún tipo de soporte o de portador de significación.

c) Es preciso además que existan un sujeto o sujetos que expresen el significado y otro sujeto o sujetos al que este significado vaya dirigido3.

¿Por qué las ciencias humanas son hermenéuticas? ¿De dónde nos viene la idea de que los hombres y sus acciones forman un objeto o conjunto de objetos que responden a estas condiciones? Precisamente porque la noción de significado tiene un lugar esencial en la caracterización del comportamiento humano. Como señala Gadamer en el prólogo a la segunda edición de Verdad y Método, "la analítica Heideggeriana de la temporalidad ha demostrado de manera convincente que comprender no es un modo de comportamiento del sujeto entre otros, sino el modo de ser del Dasein mismo"4. Comprender es encontrar el significado. Pero ¿Qué entendemos por significado? Taylor habla de "significado experiencial” (experiential meaning), como aquel que se refiere a algo (un

3 Charles Taylor, Philosophical Papers II Philosophy and Human Sciences (Cambridge: Cambrige University Press 1985), 15-16. We need, first, an object or field of objects, about which we can speak in terms of coherence or its absence, of making sense or nonsense. Second, we need to be able to make a distinction, even if only a relative one, between the sense or coherence made, and its embodiment in a particular field of carriers or signifiers. For otherwise, the task of making clear what is fragmentary or confused would be radically impossible.(...) There is also a third condition it must meet. We can speak of sense or coherence, and of their different embodiments, in connection with such phenomena as gestalts, or patterns in rock formations, or snow crystals, where the notion of expression has no real warrant. What is lacking here is the notion of a subject for whom these meanings are. Without such a subject, the choice of criteria of sameness and difference, the choice among the different forms of coherence which can be identified in a given pattern, among the different conceptual fields in which it can he seen, is arbitrary.

4 Textes reunis par Denis Thouard, "Hermeneutique contemporaine, comprendre, interpréter, connaitre, Preface (1965)", en George Gadamer, Verité et Methode. Les grandes lignes d'une herméneutique philosophique (Paris: J. Vrin 2011), 118. L'analitique heideggerienne de la temporalité du Dasein humain a montré de manière convaincante, selon moi, que comprendre n' esta pas un mode de comportament du sujet parmi d'autres, mais le mode d'être du Dasein lui même ( traducción del autor). 
portador de sentido), en un determinado campo de significados relacionados y para un sujeto (para que alguien lo entienda) 5 . Taylor se refiere a la concepción ordinaria de coherencia y de sentido. Le damos sentido a una acción cuando hay una coherencia entre la acción del agente y el significado que se le da. Su acción "no tiene sentido" hasta que no encontramos esta coherencia. Una buena explicación es la que da sentido a un comportamiento. Pero no basta con esta simple "búsqueda de coherencia" para caracterizar el acercamiento hermenéutico. En la relación hermenéutica, la relación entre significado experiencial y "portador de significado” engloba a uno mismo, es conocimiento de sí. La coherencia que buscamos está constituida parcialmente por nuestra propia auto-interpretación como agentes incorporada al flujo de las acciones que queremos interpretar. La comprensión de los significados conlleva, en buena medida, nuestra auto-comprensión ${ }^{6}$.

Así, en la opinión de Taylor, debería ser objeto de las ciencias del hombre la lectura del significado de las acciones humanas y de los sucesos y contextos en los que estas intervienen.

\section{CIENCIAS HUMANAS Y SIGNIFICADO}

La desaparición del significado - y la desconsideración de la profunda relación de pertenencia que como humanos tenemos con los objetos de las ciencias humanas- proviene de una epistemología de la ciencia que considera como el único medio provechoso de obtener conocimiento, la obtención sistemática de datos positivos caracterizados por su

\footnotetext{
5 Taylor, Philosophical Papers..., 23.

6 Taylor, Philosophical Papers..., 26 If this is so, then we have to think of man as a selfinterpreting animal. He is necessarily so, for there is no such thing as the structure of meanings for him independently of his interpretation of them; for one is woven into the other. But then the text of our interpretation is not that heterogeneous from what is interpreted; for what is interpreted is itself an interpretation; a self-interpretation which is embedded in a stream of action. It is an interpretation of experiential meaning which contributes to the constitution of this meaning. Or to put it in another way: that of which we are trying to find the coherence is itself partly constituted by selfinterpretation.
} 
objetividad. Esta prevalencia de los elementos objetivamente verificables determinó que el significado quedara oculto o se considerara irrelevante a los efectos de la ciencia. Dilthey, primero, y después Gadamer pusieron de relieve la inanidad de la equiparación epistemológica entre ciencias naturales y ciencias del espíritu, explicando la distinción en base a los ejes de explicación (propia de las ciencias naturales) y comprensión (propia de las ciencias humanas), restableciendo a través de la hermenéutica la importancia del significado.

El "giro linguístico" de la filosofía vuelve a potenciar la idea de significado sobre la de "positividad". Cada vez que nos referimos a los seres humanos lo hacemos en términos evaluativos, nunca positivos. La idea de que segregamos los términos "valorativos" y usamos su ausencia como un criterio para establecer el carácter científico de una disciplina no puede sostenerse. Porque, como dice Rorty, no hay manera de evitar que alguien utilice un término evaluativamente ${ }^{7}$. Si esto es así, el conocimiento como simple constatación de hechos, no existe ni ha existido nunca. El "hecho bruto" no es otra cosa que un hecho cuyo valor queda oculto. Rorty reconduce los términos explicación y comprensión a dos intenciones subyacentes en el uso del lenguaje: la explicación es una observación de los hechos a través de un lenguaje que persigue la representación lo más clara posible de algo externo al propio lenguaje que pretende controlar y predecir. La explicación responde a la pregunta ¿Cómo funciona? La comprensión, en cambio, utiliza un lenguaje evaluativo dirigido a contestar a la pregunta ¿Qué puedo hacer? No nos encontraríamos ante una mirada teorética y una mirada hermenéutica, sino, en la terminología utilizada por Rorty, con dos vocabularios diferentes ${ }^{8}$.

7 Richard Rorty, Consequences of Pragmatism (Essays: 1972-1980) (Minneapolis: University of Minnesota Press 1982), 196: Whatever terms are used to describe human beings become "evaluative" terms. The suggestion that we segregate the "evaluative" terms in a language and use their absence as one criterion for the "scientific" character of a discipline or a theory cannot be carried out. For there is no way to prevent anybody usingany term "evaluatively".

8 Rorty, Consequences of Pragmatism..., 197. "Explanation" is merely the sort of understanding one looks for when one wants to predict and control. It does not contrast with something else called "understanding" as the abstract contrasts with the concrete, or the artificial with the natural, or the "repressive" with the "liberating." To say that something is better "understood" in one vocabulary 
Sostener la existencia de unas ciencias humanas con un objeto limitado a la verificación o a la representación correcta de lo real, deja fuera del conocimiento lo que realmente necesitamos que no es otra cosa que leer el significado de lo significativo y, con ello, tener información que nos ayude a decidir qué hacer. Y este significado está total o parcialmente constituido por autodefiniciones, que son, en un sentido, ya interpretaciones. El ser humano se va autodefiniendo y el "significado" le orienta en ese permanente estado de apertura. Los significados intersubjetivos, encarnan necesariamente una cierta autodefinición, una visión del agente y de su sociedad que es la que la sociedad o la comunidad tiene de sí misma.

No es posible "presentar" el significado con datos brutos y, por lo tanto, nos encontramos con ciencias basadas en lecturas, no en verificaciones. Sin embargo, Heidegger nos advierte contra "el círculo vicioso hermenéutico”. Un comprender en función de lo ya previamente comprendido nos lleva a un círculo que puede ser un círculo vicioso cuando conduce a una mera "ratificación" de los prejuicios, a una simple "demostración” de lo que previamente se tenía por cierto. Si ponemos en conexión determinados signos como, por ejemplo, una crisis demográfica, el crecimiento de actitudes insolidarias, la falta (percibida) de un

than another is always an ellipsis for the claim that a description in the preferred vocabulary is more useful for a certain purpose. If the purpose is prediction, then one will want one sort of vocabulary. (...) In the case of evaluating artillery fire, for example, the predictive vocabulary of ballistics will do nicely) In the case of evaluating human character, the vocabulary of stimulus and response is beside the point.) To sum up this point: there are two distinct requirements for the vocabulary of the social sciences: (1) It should contain descriptions of situations which facilitate their prediction and control (2) It should contain descriptions which help one decide what to do. "Explicación" es simplemente el tipo de comprensión que uno busca cuando uno quiere predecir y controlar. Eso no contrasta con algo más llamado " comprensión" como el contraste entre abstracto y concreto o lo artificial o no natural o lo "represivo" o lo "liberador". Decir que algo es mejor " comprendido" en un vocabulario que en otro siempre es una elipsis para la pretensión de que una descripción en el vocabulario preferido es más útil para cierto propósito. Si el propósito es la predicción, entonces uno preferirá un tipo de vocabulario. En el caso de la evaluación del fuego de artillería, por ejemplo, el vocabulario predictivo de la balística nos servirá. En el caso de la evaluación del carácter humano, el vocabulario del estímulo y la respuesta no tiene demasiada relevancia. En conclusión,: hay dos distintos requerimientos para el vocabulario de las ciencias sociales: (1) Debería contener descripciones de situaciones que faciliten su predicción y control (2) Debería contener descripciones que nos ayuden a decidir qué hacer (traducción del autor). 
propósito o tarea colectivos, la fragmentación de las estructuras sociales y políticas, la aparición de reclamaciones identitarias de distinta naturaleza podría llevarnos a interpretar la existencia de una "crisis de valores", una conclusión que los datos brutos, nunca nos daría (sería epistemológicamente imposible que nos la diera). El círculo hermenéutico no se abriría si nos negamos a la relación significativa, si los datos son para nosotros brutos, sin significado. Se produciría un círculo vicioso si el científico social sólo tomara aquellos datos que ratificaran la tesis inicial, despreciando los otros ${ }^{9}$. Este vicio circular se convierte en una distorsión del sentido. El círculo permanecería abierto si todos los datos y todas las posibles significaciones fueran contempladas en la búsqueda de coherencia, aun poniendo en riesgo la tesis inicial ${ }^{10}$. Así, continúa Taylor, si nuestras lecturas no son comprendidas o no resultan convincentes para nuestro interlocutor, no hay procedimiento de verificación al que podamos recurrir. Sólo podemos seguir ofreciendo interpretaciones dentro del círculo interpretativo y apelar a una visión más profunda. Nuestro interlocutor podría pensar que la situación que vivimos no puede calificarse como "crisis de valores", sino la pérdida de las referencias comunes que articulaban la sociedad, lo que ha dado lugar a una mayor " apertura” a un proceso lógico de mayor pluralismo y al reconocimiento de " formas de vivir" de grupos que reclaman sus propias historias y sus propias voces, a nuevas inquietudes que no se conforman con una "integración” en las estructuras previas y que, por ello, reclaman cambios radicales.

9 Tal sucedería si un grupo nacionalista de un país determinado .buscara los datos que pusieran de relieve de forma coherente la situación prefigurada .como " dos grupos nacionales en el mismo país" en la cual uno de ellos está sufriendo un perjuicio por su asociación con el otro, Se produciría un circulo viciosos si el científico social sólo tomara aquellos datos históricos, económicos, sociales, culturales o políticos que ratificaran la tesis de la existencia de dos grupos separados uno de ellos "perjudicado" por el otro y que por lo tanto debe ser "liberado", despreciando u omitiendo aquellos que se puedan comprender significativamente de otra manera.

10 Taylor, Philosophical Papers..., 53. Our conviction that the account makes sense is contingent on our reading of action and situation. But these readings cannot be explained or justified except by reference to other such readings, and their relation to the whole. If an interlocutor does not understand this kind of reading, or will not accept it as valid, there is nowhere else the argument can go. Ultimately, a good explanation is one which makes sense of the behaviour; but then to appreciate a good explanation, one has to agree on what makes good sense; what makes good sense is a function of one's readings; and these in turn are based on the kind of sense one understands. 
En este punto, como sostiene Taylor, la "falta de acuerdo", tiene también un significado. Como seres humanos somos seres que se autodefinen y somos lo que somos en virtud de las autodefiniciones que estructuran nuestro mundo. Nos resulta francamente difícil aceptar definiciones, ideologías o interpretaciones que no se ajusten a nuestras definiciones estructurantes o que sean incompatibles con ellas. Es lo que Taylor llama la "brecha de intuiciones" que no sólo divide diferentes posiciones teóricas, sino también las opciones vitales que están en juego, sin ser evidente o explícito. Por eso, el círculo hermenéutico puede convertirse en un diálogo que nos interpela, no a cambiar de orientación, pero sí, al menos, hacia una opción de vida que permita una mejor comprensión de los otros.

\section{Como dice Taylor}

Así en las ciencias del hombre en la medida en que son hermenéuticas puede darse una respuesta válida al "no comprendo" que toma la forma no solo de "desarrolla tu intuición", sino más radicalmente: "cámbiate a ti mismo". Esto pone fin a cualquier aspiración a una ciencia del hombre libre de ideología. Un estudio de las ciencias humanas es inseparable del examen de las opciones entre las que los hombres deben elegir ${ }^{11}$.

Esta es la idea que Beuchot desarrolla en su teoría de la hermenéutica analógica, llamando a la phronesis a la proporción al acercamiento entre las posiciones sin asumir una posición ni equívoca ni rígida o unívoca que reconcilie a los "contrarios" sin forzar los puntos de vista iniciales hacia un enfrentamiento irreconducible ${ }^{12}$.

\footnotetext{
11 Taylor, Philosophical Papers..., 54 .Thus, in the sciences of man in so far as they are hermeneutical there can be a valid response to 'I don't understand' which takes the form, not only 'develop your intuitions', but more radical 'change yourself'. This puts an end ro any aspiration to a value-free or 'ideology-free' science of man. A study of the science of man is inseparable from an examination of the options between which men must choose. (traducción del autor).

12 Mauricio Beuchot, "Breve exposición de la hermenéutica analógica", Revista Teología 45 (2008): 491-502.
} 


\section{EL DERECHO COMO CIENCIA HERMENÉUTICA}

Las ciencias humanas son enormemente heterogéneas. Poco tienen que ver en su metodología y estructura la psicología con la economía o la semiótica con la historia o la antropología con el derecho. Si partimos de la configuración que hace Taylor de ciencia hermenéutica, el objeto principal de estas ciencias humanas será la investigación del significado de los denominados "portadores de significado", que serían en términos generales, las acciones humanas, los textos y otros registros ${ }^{13}$. No faltan, dentro de las denominadas ciencias humanas, los enfoques interdisciplinarios a búsqueda de una dimensión más significativa del estudio emprendido.

Un acercamiento simplista al derecho como ciencia humana, nos llevaría a una hermenéutica centrada en el texto normativo. De hecho, gran parte de la filosofía del derecho se ha limitado a la dimensión textual del derecho, entendido como conjunto de proposiciones prescriptivas. Según esta concepción, el significado y la coherencia que debemos buscar en derecho estaría en su producción escrita, entendida como conjunto de normas, resoluciones, dictámenes o sentencias. Sin embargo, la peculiaridad del derecho respecto a otras ciencias humanas es su doble "objeto" de atención, sus dos soportes de significado. Las ciencias humanas tienen su objeto de atención en los comportamientos, acciones o prácticas humanas (historia, sociología) o textos o relatos u obras de arte (literatura, arte, cine). El derecho, en cambio, enfoca su atención en paralelo, por un lado, a la acción humana y por otro, a aquello que la ordena y regula (el texto), que es relevante para la acción por su efecto regulador.

En derecho, lo relevante no es entender la acción de acuerdo con los parámetros significativos de relevancia social, cultural o política, ni tampoco lo es la simple extracción del significado de un texto. Lo peculiar en el Derecho es que se refiere, como conjunto de signos a interpretar, a un

13 Ricoeur amplia el objeto de la hermenéutica del texto a la acción humana, considerándola un cuasitexto. 
tipo de confrontación entre acción humana y texto, una confrontaciónllamémosla así- reguladora ya que la acción y texto están llamados en el fenómeno jurídico a mirarse permanentemente, ya sea de forma directa o "de reojo" y a extraer de este mutuo cotejo el significado relevante -el sentido de la acción humana-, tanto para los creadores, como para los destinatarios y los aplicadores del derecho.

Gadamer en su obra Verdad y Método, ya recalca la índole esencialmente práctica de la actividad jurídica y su carácter paradigmático respecto otras ciencias humanas. En el caso del derecho la aplicabilidad práctica es algo esencial: el destinatario del texto, que es al mismo tiempo su intérprete, está prefigurado por la obligación impuesta al mismo de aplicarlo El sujeto que interpreta derecho, no está simplemente llamado a la autocomprensión en un sentido práctico, está directamente interpelado a la aplicación. Las consecuencias son las siguientes:

- En toda comprensión se presupone una relación vital del intérprete con el texto. Como dice Gadamer, en toda lectura tiene lugar una aplicación, y el que lee un texto se encuentra también él dentro del mismo conforme al sentido que percibe. El mismo pertenece también al texto que entiende ${ }^{14}$. Los intérpretes de otras áreas de las ciencias humanas tienen como dimensión aplicativa, el descubrimiento de la pertenencia del intérprete a una tradición, a una forma de vida, a un lenguaje, a un marco de referencia, dentro de los cuales el objeto de la interpretación adquiere su coherencia significativa. En el caso del derecho, esta relación vital no es presupuesta o deducible, sino que es necesaria y explícita. El texto (la norma) se refiere directamente a la acción de todo sujeto implicado por ella y no hay sujeto que no se refiera con su acción a las normas jurídicas de constituyen su entorno social y cultural.

- El derecho sólo se comprende cuando se contempla desde una perspectiva aplicativa, ya sea porque se cumple o porque se ha

14 Hans-Georg Gadamer, Verdad y Metodo. Fundamentos de la Hermenéutica filosófica (Salamanca: Ediciones Sigueme, 1993), 210. 
incumplido. Como dice Gadamer, la aplicación no quiere decir aplicación ulterior de una generalidad dada, comprendida primero en sí misma. La comprensión de toda "generalidad" se produce por primera vez en el acto aplicativo, es decir, viene de la mano de la acción humana ${ }^{15}$. Por eso no podemos limitar el concepto de intérprete al aplicador (juez o funcionario). Intérprete del derecho será todo aquel cuyas acciones resulten de una manera u otra afectadas por los enunciados normativos de tipo jurídico.

- El derecho tiene en común con la moral en que en ambas materias se da la confrontación entre acción y texto regulador (o cuasitexto). La investigación jurídica ha separado la instancia jurídica de la moral a partir de dos criterios fundamentales:

a) En primer lugar el carácter formal del texto regulador en el caso del derecho, frente al carácter informal e interno del precepto moral.

b) La aplicación de los preceptos morales no se lleva a cabo en la esfera de lo público, ni por personas o instituciones encargadas públicamente de su aplicación.

Sin embargo, desde nuestra perspectiva, como veremos, la distinción capital entre derecho y moral, sin perjuicio de su entrecruzarse permanente, resulta de la posición de uno y otra respecto a la acción humana.

Pero ¿Cuál es el significado del derecho? ¿Cuáles son las lecturas de significado que podemos obtener del derecho? Una primera contestación a esta pregunta nos llevaría a la idea de Justicia. La vocación del derecho sería realizar el ideal de justicia. El problema de la Justicia se ha planteado tradicionalmente fuera de la relación norma-acción y se le ha dado una dimensión ontológica. La justicia ha sido siempre un algo, un fin, o una entidad distinta de las acciones emprendidas para alcanzarla. Justicia es una virtud para Platón y Aristóteles. Para Platón el ejercicio de la

15 Gadamer, Verdad y Metodo..., 211. 
justicia nos conduce a la República ideal. Aristóteles considera la justicia como la virtud del "justo medio", Cicerón considera que la justicia es algo que debe realizarse en la sociedad humana consistente en atribuir a cada uno lo suyo. La idea de la ley natural, tanto de origen divino como derivada de la razón, llevó a considerar que la aplicación de la ley natural llevaba automáticamente a la realización de la Justicia. Este considerar la justicia como "algo" propio que se puede "alcanzar" en abstracto se prolonga durante la modernidad ilustrada, llega hasta nuestros días y se basa en la confusión entre cuestiones de hecho (descriptivas) y de valor (evaluativas). Berlin lo describe de la siguiente manera:

La tradición central del pensamiento occidental había asumido que todas las preguntas generales eran cuestiones de hecho y por lo tanto eran contestables por aquellos que estaban en posición de conocer los datos relevantes y de interpretarlos correctamente. En alguna parte hay una solución para cualquier problema. Las cuestiones morales y políticas no diferían en este sentido del resto: preguntas como ¿por qué debo obediencia? o ¿̇cuál es la mejor vida para los hombres?, no eran diferentes de la pregunta ¿De qué se compone el agua? Puede que yo no sepa la respuesta, pero la respuesta existe. (...) A pesar de las diferencias, en todas ellas subyacen tres suposiciones: que existe un ente que es la naturaleza humana, natural o sobrenatural que pueden comprender los expertos pertinentes; que tener una naturaleza específica supone perseguir ciertas metas comunes impuestas por Dios o por la naturaleza impersonal y que perseguirlas es lo que hace a los hombres humanos; que esas metas y los correspondientes intereses y valores no pueden estar en conflicto, sino que forman un todo armonioso ${ }^{16}$.

Sin embargo, tal y como desarrollaremos después, lo justo es una valoración de los resultados de una acción humana sobre los otros seres humanos desde el punto de vista de la correspondencia: es decir, es un juicio sobre lo que le corresponde al agente de la acción por los efectos

16 Isaiah Berlin, El sentido de la realidad, sobre las ideas y su Historia (Madrid: Taurus, 1998), 249-250. 
de su acción sobre los demás en términos de recompensa o correctivo. Tiene que ver con la proporción, con lo equitativo, con lo merecido y, por lo tanto, con los resultados de una acción, no a su diseño, preparación o ejecución. Seguimos a Hart, cuando afirmamos que la Justicia se separa en estos términos de la moral ${ }^{17}$. Así un acto justo sería aquel que, en sus efectos, repercute sobre el agente en la debida proporción, recibiendo así "las consecuencias de sus actos", "su merecido". Este "retorno" de los efectos es el objeto de la "regulación": el texto normativo pretende regular la acción hacia unos efectos previstos como justos. De no conseguirlo, las normas se percibirían como carentes de significado, ya que serían injustas o permitirían lo injusto.

Una traslación de la evaluación de lo justo hacia la justicia como sistema que asegura de forma predeterminada las "justas" correspondencias supone la incorporación de la "ideología" política al vocabulario del derecho y a la confusión entre lo fáctico y lo evaluativo. En cualquier caso, nos llevaría hacia una hermenéutica de la política.

El momento en el que el iusnaturalismo asocia la ley natural, naturalmente justa, a la ley codificada (concebida como ese todo armonioso que es eso llamado Justicia), el derecho justo es aquel que está expresado a la norma. El positivismo dará el paso de considerar exclusivamente derecho sólo la norma así constreñida. El objeto del conocimiento científico del derecho serán las normas y el ordenamiento jurídico como conjunto de normas positiva. El olvido del significado en el derecho, como en el resto de las ciencias humanas, proviene de la "obsesión epistemológica"

17 Herbert L.A. Hart, El concepto de Derecho (Buenos Aires: Abeledo Perrot, 2009), 196. De un padre que ha tratado con crueldad a su hijo se dirá por lo común que ha hecho algo moralmente malo o aun malvado, o que ha transgredido su obligación o deber moral hacia su hijo. Pero sería extraño que se criticara su conducta como injusta. Esto no es porque la fuerza condenatoria de la palabra" injusto" sea demasiado débil, sino porque la crítica moral en términos de justicia o injusticia por lo común es diferente de ( y más específica) los otros tipos de crítica moral general que se adecúan a este caso particular y se expresan mediante palabras como "incorrecto", "malo" o " malvado" "injusto" sería apropiado si el padre hubiera elegido arbitrariamente a alguno de sus hijos para aplicarle un castigo más severo que a otros de ellos culpables de la misma falta, o si hubiera castigado al niño por algún desaguisado sin tomar los recaudos necesarios para cerciorarse que éste era realmente el autor. 
empeñada en reducir lo relevante a un conjunto de "datos brutos" objetivos, vacíos de contenido evaluativo. En el caso del derecho, la norma y los conjuntos de normas se constituirán como objeto de estudio propio de la ciencia jurídica en cuanto estructuras lógicas, dejando al margen la acción humana y su significado, que son las referencias imprescindibles de cualquier texto regulador.

Para contestar a la pregunta sobre el significado del derecho partiremos del estudio de la hermenéutica jurídica y de cómo se ha construido la idea de derecho desde la normatividad olvidando la acción humana y su significado.

\section{LA HERMENÉUTICA JURÍDICA}

La hermenéutica jurídica como campo de estudio dentro de la teoría del derecho se refiere al conjunto de operaciones intelectuales que debe llevar a cabo el aplicador del derecho para aplicarlo a un caso concreto.

Según Francisco Muñoz Conde:" la interpretación es una operación intelectual por la que se busca establecer el sentido de las expresiones utilizadas por la ley para decidir los supuestos contenidos en ella y, consecuentemente, su aplicabilidad al supuesto de hecho que se le plantea al intérprete". ${ }^{18}$.Según esta definición, el portador de significado al que hay que dar sentido es la norma o el enunciado jurídico que en todo caso se remite a una norma. La interpretación es interpretación de textos. Identificada por la ciencia jurídca como texto prescriptivo, la interpretación y aplicación de la norma es reductible a una operación lógica.

En la norma hay una premisa mayor o supuesto de hecho (en el que se representa una realidad) una premisa menor que es el hecho subsumible y un resultado (o consecuencia jurídica). Si la norma representa la acción de matar a una persona (el que matare a otro) y una persona ha

18 Francisco Muñoz y Mercedes García, Derecho Penal. Parte General, 6ª ed. (Valencia: Tirant lo Blanch, 2004), 121. 
matado a otra (ajuste entre la realidad y lo representado), se aplicará la consecuencia jurídica prevista (pena de prisión correspondiente). Se cumpliría el siguiente silogismo:

“dado A (la hipótesis normativa), entonces debe ser B (consecuencia legal)

Mas correctamente, dado que a es A, entonces debe ser B.

Entendiendo como a los hechos o actos humanos, A la representación de esos hechos en el supuesto de hecho y B la consecuencia jurídica.

Si los hechos descritos en la norma o la descripción de la consecuencia no "son lo bastante claras" para acotar suficientemente las "realidades" a las que se refieren se prevé la existencia de unas normas de interpretación de los enunciados jurídicos. Así, el art. 3.1 del Código Civil enumera pautas para la interpretación de las normas, los arts. 1281 a 1289 tratan «De la interpretación de los contratos», y el art. 675.5 regula aspectos de la interpretación de los testamentos

La interpretación jurídica así planteada presupone:

a) Una concepción normativista del derecho según la cual el derecho es norma, cuyo defensor principal es Kelsen ${ }^{19}$. Como señalan Viola y Zaccaria la concepción normativista, junto a otras concepciones como la realista o la iusnaturalista, responde a la idea de que existe "algo así" como la "naturaleza del derecho" como algo propio específico y ajeno a la realidad social en el que el derecho se muestra. Ronald Dworkin ha llamado a estas

\footnotetext{
19 La de normativismo es una categoría aún más compleja. Aunque sea caricaturescamente, la podemos caracterizar como la propia de aquellas teorías que ven la esencia de lo jurídico en un terreno ontológico independiente (aunque no carente de relación, por supuesto) de los puros hechos (fuerza, voluntades, sensaciones...) y de los valores (justicia, seguridad, paz...) y consistente en una peculiar forma de ser que es la forma de ser de lo normativo, del Sollen. El derecho, como objeto, cobra así su autonomía conceptual, ontológica y epistemológica, por cuanto que lo que hace que una norma sea parte del derecho no es ningún hecho en sí mismo (que alguien lo mande o lo acate), ni ningún juicio sobre su contenido, sino su relación con otras normas del mismo sistema jurídico que le transmiten ese especial sello o carácter definitorio de la validez jurídica, del ser derecho y no (meramente) otra cosa Juan Antonio García Amado, "Filosofía hermenéutica y derecho", Azafea. Revista de filosofía 5 (2003): 191-211.
} 
concepciones «teorías semánticas del derecho», porque buscan la definición del derecho como si fuera un objeto preexistente a la realidad social que hay que interpretar de acuerdo con reglas inmanentes al mismo ${ }^{20}$. Como en toda reducción racionalista-positivista se considera el derecho como un conjunto de elementos objetivos cognoscibles en sí mismos, en este caso las normas y las relaciones de las normas entre sí. El paradigma de norma es la ley, considerada como disposición general y abstracta que es comprensible en sí misma en su generalidad y abstracción. Sin embargo, como hemos expuesto anteriormente, el derecho no es un saber objetivo o positivo, sino que es un saber práctico. Es decir, el conocimiento de la norma, no nos lleva al conocimiento del derecho. Conocemos el derecho cuando aplicamos la norma (puesto que la generalidad no es otra cosa que su aplicabilidad). No hay dos momentos uno de conocimiento de la norma y otro de aplicación, sino que ambas cosas se producen simultáneamente: el derecho se conoce cuando la norma se encuentra con lo que está referido en ella

b) Otro presupuesto de la interpretación jurídica entendida al modo tradicional es que el contenido material del derecho "las expresiones utilizadas en la ley” puede ser cualquiera. Para Kelsen el único bien general que el derecho positivo se propone alcanzar es el bien formal de la paz, es decir, de la tendencial eliminación del uso de la fuerza salvo en los casos determinados por la ley. Y es por este motivo que el derecho es definido como la técnica social que consiste en obtener la deseada conducta social de los hombres mediante la amenaza de sufrir una coacción en caso contrario $^{21}$.

20 Francesco Viola y Giuseppe Zaccaria, Derecho e Interpretación. Elementos de teoría hermenéutica del Derecho (Madrid: Dickinson, 2007), 38.

21 Hans Kelsen, Teoría pura del Derecho (Buenos Aries: Eudeba, 2009), 58. 
c) El sistema del derecho es un sistema cerrado. La norma se explica a sí misma a través de otras normas El derecho positivo está perfectamente en disposición de contener, mantener y reproducirse a sí mismo. Todos los problemas de interpretación y aplicación del derecho pueden resolverse a través de mecanismos inmanentes propios del derecho

Sin embargo, la convicción compartida por la hermenéutica jurídica moderna es que el acto aplicativo no puede reducirse a una deducción automática a través de la subsunción de los hechos en el supuesto de hecho. El acto del intérprete es mucho más complejo. El ilustre filósofo Arthur Kaufmann lo expresa de la siguiente manera

La ley no es realidad sino sólo posibilidad de derecho. Si es cierto que el derecho no surge sólo de la ley, para que el derecho se origine deberá la ley ser completada por algo que se halle fuera de ella. Esta opción apenas si es hoy discutida. Pero casi siempre se teme derivar consecuencias de ella o no se captan en absoluto, porque, como se ha indicado más arriba, se acepta acríticamente la imperfección de la ley como un hecho esporádico, como tantas otras muestras de lo imperfecto de nuestro mundo. Pero el inacabamiento de las leyes no es en modo alguno una imperfección o un fallo sino que se apoya necesaria y apriorísticamente en la esencia misma de la ley. La ley ha de ser válida para la realidad, pero la realidad es indefinidamente pluriforme y se encuentra en incesante cambio. Precisamente por esta variedad y alterabilidad de los contenidos vitales no puede formularse una ley de manera concluyente y unívoca, aunque ello fuese posible (que no lo es, como ha puesto de manifiesto la inutilidad de las prohibiciones de interpretación). La ley ha de concretizar siempre en la respectiva situación histórica; sólo en el caso y a través del caso se hace comprensible lo que "piensa" la ley. La metodología tradicional ha errado, pues, cuando ha creído que la respuesta a la cuestión de si el texto legal "piensa" un determinado contenido material, podría encontrarse en la ley misma a través de la "interpretación". En realidad, hay que 
preguntar siempre también al contenido material (adelantado al menos teóricamente) si el texto legal le resulta adecuado, pues de lo contrario sería imposible una "comprensión" de la "correspondencia" (adaequatio) existenteentre contenido material y texto legal. Comprender un texto no es por tanto algo puramente receptivo, sino un proceder práctico y conformador ${ }^{22}$.

Continúa diciendo Kaufmann que la hermenéutica jurídica no dice con todo esto nada que no haya sido siempre admitido y practicado por doquier. Se limita a sacarlo a la luz rompiendo con ello claramente algunas ilusiones, sobre todo, la ilusión de que la aplicación del derecho sea una subsunción exacta del caso jurídico bajo una ley (comprensible e interpretable por sí sola).

El problema es que se ha construido todo lo que entendemos como derecho a partir de esa visión incompleta. Descubierta la complejidad oculta del acto aplicativo, surgen ahora problemas inadvertidos hasta el momento, problemas que afectan tanto a la creación del derecho, como a la actividad jurídica propiamente dicha de los ciudadanos y de los aplicadores formales del derecho.

Teniendo en cuenta que aquello a lo que se refiere la norma es la acción humana, en el siguiente apartado intentaremos hacer una relectura aproximativa y primaria del fenómeno jurídico desde la perspectiva de la doble orientación de la norma hacia la acción humana y de la acción humana hacia la norma.

\section{DERECHO Y ACCIÓN}

En primer lugar, el fenómeno jurídico no puede reducirse a los aspectos lógico normativos. El supuesto de hecho de la norma o del enunciado normativo no es un "dato objetivo", una representación perfecta de

22 Arthur Kaufmann, "Entre iusnaturalismo y positivismo hacia la hermenéutica jurídica”, Anales de la Cátedra Francisco Suárez 50 (2016): 139. 
la realidad regulada, sino un elemento de significación y coherencia necesario para que el intérprete abra el círculo hermenéutico. El círculo hermenéutico pone en relación de significado el texto regulador con la concreta práctica social a la que se refiere y al campo semántico de las acciones humanas que la integran: el quién, el que, el cómo y el por qué. El derecho cobra coherencia y sentido a través de un continuo reenvío de significados del enunciado normativo a las acciones humanas y sus circunstancias y viceversa Así, por un lado, tenemos un texto creado a través del lenguaje que pretende englobar en una fórmula significativa una acción o una de serie acciones humanas o las circunstancias o efectos de las mismas y, por otro lado, tenemos la inconmensurabilidad de las situaciones a las que puede dar lugar la acción humana. Es evidente que es imposible que la norma como texto así caracterizado pueda dar respuesta "por sí misma" a esa inconmensurabilidad, por muy perfecta que sea desde el punto de vista técnico. Un intérprete que justifique la aplicación de la norma sólo por sí misma incurriría en la pura arbitrariedad. Nos encontraríamos en un círculo hermenéutico vicioso. Hart describe esta situación en su obra El concepto de Derecho:

Sí el mundo en que vivimos estuviera caracterizado únicamente por un número finito de notas y estas, junto con todos los modos posibles en que pudieran combinarse, fueran conocidas por nosotros podríamos formular provisiones por adelantado para toda posibilidad. (...) Obviamente este mundo no es el nuestro. Esta incapacidad para anticipar trae consiguo una relativa indeterminación de propósitos. Cuando osamos formular una regla general de conducta( por ejemplo la regla de que no pueden entrar vehículos en un parque) (...)podemos tener en cuenta ciertos ejemplos claros: ( el automóbil, el ómnibus la motocicleta)

Sin embargo, continúa Hart estos casos claros no acotan todas las posibilidades que podrían incluirse en la necesidad de mantener la tranquilidad en el parque, por lo que nuestro propósito al legislar es 
indeterminado y requiere ejercer nuevas posibilidades de elección (por ejemplo para impedir el patinete eléctrico). Hart añade que

(...) Los diferentes sistemas jurídicos, o el mismo sistema en distíntas épocas, pueden ignorar o reconocer en forma más o menos explícita tal necesidad de un ejercicio adicional de elección en la aplicación de las reglas generales a casos particulares El vicio conocido en la teoría jurídica como formalismo o conceptualismo consiste en una actitud hacia las reglas verbalmente formuladas que procura encubrir o minimizar la necesidad de tal elección, una vez que la regla general ha sido establecida. Una manera de hacer esto es congelar el significado de la regla, de modo que sus términos generales tengan que tener el mismo significado en todos los casos en que su aplicación esta de por medio. Para asegurar esto podemos aferrarnos a ciertas características presentes en el caso obvio, e insistir en que ellas son necesarias y suficientes para que todo aquello que las posea queda comprendido por la regla cualquier sean las restantes características que puedan faltarle y cualesquiera sean las consecuencias sociales que resulten de aplicar la regla de esta manera. Hacer esto es asegurar un grado de certeza o predicibilidad al precio de prejuzgar ciegamente lo que ha de hacerse en un campo de casos futuros, cuya composición ignoramos. Así habremos conseguido, por cierto resolver por adelantado, pero también a oscuras, cuestiones que sólo pueden ser razonablemente resueltas cuando se presentan y son identificadas ${ }^{23}$.

Un ejemplo claro de la necesidad de adaptación de las regulaciones lo vemos con la llegada de nuevas tecnologías a las actividades regladas: por ejemplo en la aplicación de las normativas tradicionales del sector servicios a actividades generadas a través de plataformas digitales ${ }^{24}$. Esta

23 Hart, El concepto de Derecho..., 161.

24 ¿Debe aplicarse la normativa laboral a los repartidores de plataformas digitales? ¿ Debe equipararse el alquiler con conductor contratado a través de plataforma digital con la normativa del taxi?. Estos son dos debates jurídicos abiertos en la actualidad en la sociedad espanyola en los que lo que està en juego es una aplicación formalista o no de las normes reguladoras laborales y mercantiles. 
rigidez formalista pone en peligro las prácticas sociales a las que la norma se refiere.

En segundo lugar, tal y como hemos apuntado no sólo tiene condición de intérprete el juez. El derecho lo interpretan y aplican todos los miembros de la comunidad jurídica: lo mismo es intérprete el "legislador", como el ciudadano destinatario de las normas, como el que está llamado en sentido propio a aplicarlas, ya sea funcionario o juez. Sin embargo, el intérprete por antonomasia, el que tiene que entender como presupuesto vital el derecho es el ciudadano al que van dirigidas, el que está directamente obligado a contrastar sus acciones y las circunstancias que las envuelven con las normas jurídicas. Como señalan Viola y Zaccaria colocarse en el punto de vista del legislador, del jurista, del juez o del funcionario es sin duda necesario, pero es cierto que estas ópticas particulares no tienen una justificación en sí mismas, porque reenvían de cualquier modo en sentido funcional al uso que el ciudadano ha hecho, hace o hará del derecho. ${ }^{25}$

En tercer y último lugar, una concepción normativista del derecho olvida que sociedad y Derecho (entendido como conjunto de reglas) son co-constitutivos. La acción humana es el referente ineludible del texto jurídico y ambos son imposibles de separar por lo que el origen del derecho hay que buscarlo no en las normas, sino en los propios fundamentos de la vida social. La realidad social se constituye desde un entramado de significados compartidos por los individuos, gran parte de los mismos referidos a un orden social. En este marco referencial están los valores prácticos y materiales (lo bueno, lo malo, lo correcto, lo incorrecto, lo necesario, lo prescindible lo prudente, lo indeseado, lo eficaz, lo equitativo) que están proyectados ineludiblemente sobre los hechos, las acciones, los comportamientos, los contextos sociales. El marco referencial nos sirve como estructura de anticipación de nuestro ser con los otros, es decir, nos proporciona guías de conducta ya sean de naturaleza social,

25 Viola y Zaccaria, Derecho e Interpretación..., 62. 
moral o propiamente jurídica. La actividad humana es, ab initio, desde el primer momento en el que se puede hablar de ella, una actividad guiada y el derecho es una de esas guías, quizá la más explícita de todas. Los acercamientos teóricos al derecho, ya sean desde una perspectiva normativista o realista o iusnaturalista, contemplan el derecho como instrumento formal, como una entidad externa al ser humano que limita su eficacia sobre el individuo a la existencia de una sanción jurídica, la amenaza de un castigo o la promesa de un premio, pero olvidan la dimensión fundamental de guía para la acción en un sentido mucho más amplio y significativo.Pero ¿qué caracteriza al derecho como guía de acción?, o dicho de otra manera, ¿con qué fines pretende el derecho guiar la acción humana? Según Viola y Zaccaria26 el derecho sirve a dos fines fundamentales:

a) El derecho coordina las propias intenciones con las de los otros partícipes en la vida social. Desde este punto de vista su función es la de hacer posible el proyectar un futuro dependiente del comportamiento de otros. Esta es la clave de la coordinación social. La función del derecho es por lo tanto regular la coordinación de los actores sociales haciendo sus acciones previsibles, con vistas a hacer posible la vida en sociedad a través de la planificación.Como dicen Viola y Zaccaria: los aspectos intercurrentes en las relaciones sociales no son sólo fácticos, es decir, concernientes a lo que harán los otros, sino también movidos por la convicción de que los otros están en algún sentido obligados a comportarse de un cierto modo y a tener a su vez un cierto tipo de expectativas, que esto es su deber, de modo que nosotros podemos legítimamente pretender que se acomoden a él ${ }^{27}$. La modalidad de cooperación así establecida necesita del derecho no sólo para poder coordinar la acción propia con la ajena, sino también para en el caso de que no se hagan efectivas las obligaciones asumidas

26 Viola y Zaccaria, Derecho e Interpretación..., 61 y ss.

27 Viola y Zaccaria, Derecho e Interpretación..., 66 
se puedan poner en marcha los mecanismos de aplicación del derecho. La coordinación jurídica se convierte así en un factor clave para la socialización ya que condiciona las experiencias de los destinatarios de las normas garantizando la previsibilidad, la estabilidad necesaria para ciertas opciones vitales y no para otras. En este sentido. el derecho da consistencia al proyecto humano.

b) Pero el derecho como estructura del significado no responde solamente a la necesidad de coordinar las acciones de los diversos participantes en la vida social, sino que también asegura dicha coordinación se ajuste a valores compartidos ${ }^{28}$. Esos valores tienen su origen en el núcleo de verdades compartidas que nos representamos como necesarias para la subsistencia de la sociedad. Este paso del valor a la norma es explicado por Walzer en su teoría sobre lo denso y lo tenue. Según él, los términos normativos y morales formalizados y tipificados en los códigos jurídicos de un país y en su concepción de justicia, sólo pueden formularse universalmente (de manera tenue) si previamente éstos se hallan anclados en concepciones "densas", significativamente relevantes para quienes les atribuyen un sentido social real y específico ${ }^{29}$.

La traslación del "valor" a la norma jurídica se produce incorporando el valor a las definiciones de conductas que contienen las normas o que se contemplan, a veces no explícitamente, en las mismas. Así, el derecho civil contiene la prohibición de aprovecharse de una posición de privilegio en la contratación a través de la prohibición del abuso de derecho o prioriza el interés superior del menor en las relaciones familiares. Las normas laborales se dirigen a atenuar la dependencia social del trabajador respecto a su empresario y las normas administrativas pretenden garantizar los derechos de los administrados frente a los privilegios de la administración. Sin embargo, esta incorporación de lo moral al derecho,

28 Viola y Zaccaria, Derecho e Interpretación..., 71 y ss.

29 M. Walzer, Thick and Thin. Moral arguments and Abroad (Indiana, University of Notre Dame Press, 1999). 
sólo hace que mute la naturaleza de las reglas: de reglas morales, pasan a convertirse en reglas jurídica Pero, como veremos, la incorporación del componente moral al derecho se realiza a través de la labor interpretativa del destinatario del derecho, que con la norma en la mano debe "saber que hacer" y construir su propio "modelo de compromiso". Lo veremos cuando hablemos del destinatario de las normas como intérprete del derecho.

\section{EL PUNTO DE VISTA EXTERNO Y EL PUNTO DE VISTA INTERNO}

Sin embargo, estas dos funciones -la de coordinación y la de encarnación de valores sociales- que Viola y Zaccaria consideran las propias del derecho, no agotan, a nuestro juicio, la totalidad del fenómeno jurídico como tensión significativa entre acción y texto regulador. Falta la perspectiva "interna" del derecho, la perspectiva del destinatario de las normas. Como recogen Viola y Zaccaria, la primera teoría contemporánea del derecho que se abre conscientemente a esta perspectiva interna del derecho es la de Herbert Hart. En su obra "El concepto de derecho" hace referencia a un punto de vista externo del derecho y a un punto de vista interno ${ }^{30}$. El primero corresponde al del observador que examina, por un lado, las regularidades derivadas de la aplicación de las normas y, por otro, las reacciones del grupo social y es capaz de predecir estas últimas en base a estas observaciones. El punto de vista interno, en cambio, es el del destinatario del derecho. Como afirman Viola y Zaccaría, desde este punto de vista, el derecho es un componente del proceso de deliberación que lleva a las decisiones y, consecuentemente, a las acciones. Puesto que este proceso está constituido desde el sopesar las razones en pro y en contra, entonces también el derecho debe ser considerado como un complejo de razones para la acción, es decir, de razones para ejecutar una determinada acción o para abstenerse.de realizarla ${ }^{31}$. El punto

30 Hart, El concepto de Derecho..., 111

31 Viola y Zaccaria, Derecho e Interpretación..., 51 
de vista externo e interno son reconducibles a los distintos "vocabularios" de la "explicación" y la "comprensión" de los que hablaba Rorty y a los que nos hemos referido anteriormente.

Desde el punto de vista interno, hemos de poner de relieve que ninguna regla social tiene fuerza motivacional propia, salvo que queramos reducir el derecho a un instrumento para dirigir comportamientos mediante la amenaza del uso de la fuerzaa ${ }^{32}$. Aquí la analogía del juego es suficientemente explicativa: los jugadores no juegan para cumplir las reglas del juego, sino para ganar o para divertirse. Ello es así porque el juego no está diseñado para las reglas sino las reglas para el juego. Las reglas guían la acción del jugador, pudiendo anticipar en base a ellas el comportamiento de los demás jugadores. Así las cosas, no es la norma lo que nos induce a "hacer cosas" que no queremos hacer, como ir a trabajar todos los días, sino que es el conjunto formado por las prácticas sociales y su regulación lo que nos lleva a una determinada acción o comportamiento orientado. Sin embargo, a la pregunta de ¿Cuál es el papel del derecho allí donde aparece? no es posible dar una respuesta unívoca. Si resumimos nuestras prácticas sociales veremos que en algunas hay derecho y en otras no y que en algunas hay más derecho que en otras. En la familia, el vehículo utilitario de motor, la empresa, el trabajo, el comercio, la democracia etc existe un componente jurídico-normativo pero resulta evidente que estos asuntos y contextos no son sólo "derecho". Son muchas cosas y entre ellas "hay derecho". El derecho se justifica allí donde se entiende que las prácticas sociales "requieren" de soporte normativo. "Hacer cola" es una práctica social que orienta la conducta de las personas e implica un conocimiento de su función ( ordenar la atención a un numeroso grupo de personas garantizando la prioridad con una secuencia temporal), pero no suele requerir del derecho.La disolución del régimen económico matrimonial en caso de separación y divorcio requiere,

32 Así lo hace Kelsen cuando define Derecho como la técnica social que consiste en obtener la deseada conducta social de los hombres median te la amenaza de sufrir una coacción en caso contrario 
en cambio, la intervención del derecho porque es probable que sin dicha intervención -y la posibilidad de imponer coactivamente lo ordenado por un tercero en caso de descuerdo- no se alcanzaría el efecto propio del divorcio que es la recuperación la autonomía personal y económica de las partes en un vínculo que se percibe como creado y disuelto libremente.

Felipe Curco Cobos, comentando a Rorty, sostiene que la razón que las normas dan para actuar (su carácter obligatorio) es siempre de carácter pragmático-hermenéutico. En este sentido lo que Rorty señala es que las normas son válidas en el contexto de círculos etnocéntricos (culturales). Estos círculos compendian una serie de valores, supuestos, expectativas, desde cuya lectura pueden descifrarse los códigos facultativos donde se define qué vale como norma. Dicha explicación es a su vez hermenéutica y pragmática, pues supone que descifrar la auctoritas de las normas implica una previa comprensión de la estructura políticocultural global en las que éstas se originan, a la vez que dicha comprensión requiere interpretar la función práctica que tales normas cumplen en el afianzamiento de la estructura en la cual se incardinan 33.

Esta posición se opone claramente a la distinción que hace el positivismo entre el mundo de la norma y el mundo de la realidad que se refleja en la noción de "falacia naturalista". La noción de falacia naturalista sostiene la imposibilidad de deducir de enunciados descriptivos otros enunciados de carácter prescriptivo o valorativo, es decir, extraer de lo que "en concreto es", normas que determinen lo que "debe ser". Sin embargo, en una concepción hermenéutica del derecho como la nuestra, en la que la acción humana y la norma se construyen la una a la otra, la superación de la idea de falacia naturalista se consigue contestando de manera simple a dos preguntas. La primera es ¿́por qué aparece la norma? La segunda, ¿qué induce a las personas a cumplirlas? La contestación a la

33 Felipe Curco Cobos, “¿Fue Richard Rorty un positivista jurídico? (A Propósito de la Oxford Amnesty Rorty's Lecture de 1993)”, Isonomía [online]. 35 (2011): 119-141. Consultado el 24 de marzo de 2019, http://www.scielo.org.mx/scielo.php?script=sci_arttext\&pid=S140502182011000200004\&lng=es\&nrm=iso. 
primera pregunta se encuentra en la definición de pautas normativas que son, o bien "la mejor idea que tenemos actualmente para direccionar y trascender lo que está sucediendo" o bien son "modelos adoptados en base a diversas razones fácticas e históricas" por un grupo social34. En ambos casos nos encontramos con significados compartidos que orientan las acciones, en primer lugar para corregir lo que se percibe como deficiencias y en segundo lugar para mantener lo que se percibe como adecuado (o justo). La contestación a la segunda pregunta es más simple todavía: las personas cumplen las normas porque obtienen ventajas de diversa índole de ese cumplimiento en el contexto de las prácticas sociales consideradas.

Así nos encontramos que la función "practica” del derecho es diferente según intervenga en unas o en otras instituciones o contextos sociales y esto afecta a su carácter orientador. Mientras en las relaciones de amistad inter pares, la norma jurídica no se muestra, salvo excepciones, la norma aparece en el ámbito de la familia o la enseñanza para tratar situaciones de conflicto. Ampliando la perspectiva comprobamos que el derecho tiene una presencia sustancial en las relaciones comerciales o laborales y su presencia es sustancial en las relaciones de los ciudadanos con los órganos estatales. De aquí se deduce que, en entornos privados y ámbitos comunitarios en los que está en juego la unidad e identidad del grupo social, los sistemas normativos de tipo social o ético juegan un importante papel para orientar las acciones del grupo y resolver los conflictos sin el auxilio del derecho. En cambio, cuando entra en juego la razón “orientada a fines", en términos weberianos (en el ámbito de la empresa o de la administración) y aparece la necesidad de coordinar acciones múltiples y diversas, cada vez más complejas, la introducción de normas jurídicas se percibe como algo imperativo. Lo que conlleva también una reformulación de los valores en las normas a la vista de las necesidades estratégicas (por ejemplo, el derecho a la intimidad se convierte en una legislación masiva sobre protección de datos). Las

34 Cobos, “¿Fue Richard Rorty un positivista jurídico?”. 
instituciones de los códigos civiles se adaptan a los contextos instrumentales. Así aparece el derecho administrativo, el derecho fiscal o de la Seguridad Social. Esta ubicuidad de las normas en los ámbitos públicos y de la administración, constituyendo realidades puramente jurídicas al servicio de sí mismas, parece culminar el sueño positivista de un sistema normativo autosuficiente. La acción humana parece alejarse de la norma. Pero este alejamiento sólo es ilusorio. El origen de estos sistemas reguladores se encuentra, por un lado, en la separación de poderes del estado y por otro en el "intervencionismo estatal”. La idea de " separar funciones estatales" e " intervenir" supone un grado más en la escala por encima del "guiar u orientar". Así mientras la normativa reguladora del alquiler de inmuebles urbanos guía la conducta de arrendatarios y arrendadores en aquella práctica social en la que aparece ( el uso por una persona o personas de la vivienda de otra), las normas de la Seguridad Social o tributarias “ constituyen" verdaderas estructuras sociales que no existirían sin las normas que las consituyen ( las pensiones, los impuestos, los tribunales), es decir, sus normas son "constitutivas" 35 . Es la labor de estas estructuras constituidas por la norma la que, en un segundo grado, “ interviene” en el ámbito de la acción humana. Esta intervención se diferencia de la simple orientación. Aquí el derecho, en lugar de guiar las acciones propias con las acciones previsibles de otros actores, busca incidir directamente en la acción humana potenciándola a través de prestaciones o de normas de fomento o conteniéndola a traves de la exigencia de contribución o ejerciendo la represión. Buscan, directa o indirectamente, configurar la autonomía humana. Se atribuyen ventajas o beneficios, estímulos o se exigen contribuciones expresamente creadas por la norma. Mientras las normas del arrendamiento o de la compraventa, modelan la acción de los participantes sobre la base de una previsibilidad mutua de las acciónes

35 Nos referimos aquí a la diferencia que hace Searle entre reglas regulativas ( aquellas que regulan una actividad que existiría sin la regla) y reglas constitutivas ( aquellas que se refieren a una actividad cuya existencia es dependiente de la misma regla y la constituyen: por ejemplo las reglas del ajedrez no sólo regulan el ajedrez, sino que lo constituyen, lo estructuran) John R. Searle, "What is an institution?", Journal of Institutional Economics 1 (2005): 9. 
dentro de intereses ponderados y valores compartidos, las normas provenientes del aparato intervencionista del estado incorporan a la acción humana, para bien o para mal, motivos, previsiones y valores que no son los de otros agentes, sino los del estado, con el fin de enriquecerla, activarla o desactivarla para los propios fines que el estado ha establecido, entre ellos, el fin de sostener el funcionamiento del estado.

Según Taylor, en el ámbito político se muestra el carácter constitutivo de ciertas normas básicas. Son reglas, en efecto, que atañen a la constitución más íntima de la actividad reglada, sin las cuales dicha actividad no existiría. Taylor opina que:

Los actores pueden tener toda clase de creencias y actitudes que pueden ser correctamente consideradas como sus creencias y actitudes individuales (...). Ellos traen estas cuestiones con ellos a sus negociaciones y luchas por satisfacerlas. Pero lo que no traen a las negociaciones es el conjunto de ideas y normas constitutivas en sí mismas de la negociación. Estas deben ser el patrimonio común de la sociedad antes de que pueda haber algún problema susceptible de entrar o no en la negociación. Estos no son significados "subjetivos" propiedad de uno o de algunos individuos, sino significados intersubjetivos, que son constitutivos de la matriz social en la cual los individuos se encuentran a sí mismos y actúan ${ }^{36}$.

Estas creencias y significados nucleares pueden cambiar en el tiempo o ser diferentes en una cultura o en otra, pero lo que es seguro es que siempre existirá en toda sociedad un núcleo de prácticas, ideas y normas innegociables que tendrán una gran dosis de sustancia ética. Toda norma

36 Taylor, Philosophical Papers..., 16. The actors may have all sorts of beliefs and attitudes which may be rightly thought of as their individual beliefs and attitudes, even if others share them; they may subscribe to certain policy goals or certain forms of theory about the polity, or feel resentment at certain things, and so on. They bring these with them into their negotiations, and strive to satisfy them. But what they do not bring into the negotiations is the set of ideas and norms constitutive of negotiation themselves. These must be the common property of the society before there can be any question of anyone entering into negotiation or not. Hence they are not subjective meanings, the property of one or some individuals, but rather inter-subjective meanings, which are constitutive of the social matrix in which individuals find themselves and act. 
tiene un "eco" de este núcleo innegociable (como señala Walzer), pero hay reglas que se estiman "constitucionales" porque establecen las bases previas de toda actividad reglada que no sería tal sin esas bases: tal consideración tiene en nuestro derecho las normas que regulan los derechos intrínsecos a la dignidad de las personas o la igualdad de oportunidades, así como las normas relativas a los derechos fundamentales. No queremos decir con ello que todas las normas constitucionales sean innegociables, sino que lo innegociable funciona como máximo criterio orientador, como consenso relativo a lo que orienta nuestra vida en común, esté incluido o no en las normas constitucionales.

En cuanto a la relación entre derecho y moral, ya hemos explicado que en la moral y en el derecho se produce la misma confrontación entre norma y acción. Sin embargo, la acción humana se orienta hacia la idea que tiene el agente de "buena vida" mientras que la orientación que proporciona el derecho se refiere a la práctica social, en un sentido estratégico de consideración de medios y fines. Ambas orientaciones se cruzan necesariamente. Como afirma Ricoeur, la aspiración humana al bien incluye la búsqueda de una buena vida en una sociedad con instituciones justas. Aunque los valores morales integran el derecho a través de las normas que los incorporan y los saberes prácticos de sus intérpretes, el juicio sobre lo justo y lo injusto es el elemento valorativo específico del derecho. Ya hemos dicho anteriormente que lo justo es una valoración de los resultados de una acción sobre los otros seres humanos desde el punto de vista de la correspondencia: es un juicio sobre lo que debe revertir al actor por su acción, sobre si lo que le revierte le corresponde justamente o no. Lo justo no está separado de los criterios morales: lo justo es lo bueno o lo malo ajustado a una correlación entre las variables efecto del propio acto y consecuencia sobre el agente de dicho efecto. La ejecución de Luis XVI será justa si tal efecto era el que le correspondía a él particularmente por las consecuencias de sus actos (si estos fueron buenos o malos) sobre los demás seres humanos en su tiempo y en su lugar. El precio será justo, si los que compran el bien pagan al vendedor 
por lo que corresponde al valor del bien (bueno para ambos). ${ }^{37} \mathrm{El}$ salario será justo si los trabajadores cobran en correspondencia con el trabajo que desempeñan para el agente que fija el salario (adecuado correlativamente al trabajo). Si dijéramos, como señala Hart, que la ejecución, el salario o el precio son "buenos" no estaríamos diciendo la misma cosa. Desde esta perspectiva, una norma no podrá considerarse justa o injusta sino es por los resultados, efectos o situaciones que crean las acciones que orienta. En la medida en que el texto regulador contenga una predicción de los efectos de las acciones ${ }^{38}$, se puede valorar su "justicia" a priori y a posteriori y prever, en su caso, las oportunas correcciones. Pero el derecho no puede hacerlo sin intérpretes del derecho, es decir, sin la acción comprensiva de aquellos que se ocupan de relacionar acciones con normas: legislador, ciudadano y aplicador, ya sea funcionario o juez.

\section{LOS INTÉRPRETES DEL DERECHO}

\subsection{EL LEGISLADOR}

No suele considerarse al legislador como intérprete del derecho. Para las teorías normativistas, el legislador actúa creando el derecho desde fuera del derecho y la tarea del intérprete empieza cuando la norma ya está en vigor. En la actualidad, sobre todo en las teorías hermenéuticas del derecho la función del legislador aparece devaluada. Si la ley es algo incompleto, como dice Kaufmann, el legislador no puede tener un papel absoluto en la creación del derecho, el legislador y el juez trabajan conjuntamente en la producción de la norma. Esta devaluación

37 Un precio justo se diferencia de un buen precio, en que éste último será beneficiosos (es decir barato en su relación calidad precio) mientras que el precio justo, sería el que corresponde exactamente al ser puesto por alguien para alguien en función de un referente que establece lo que corresponde. La bondad o lo bueno no se corresponde con lo justo manteniéndose en el "justo medio" aristotélico entre lo mejor y lo peor.

38 La norma que pena el asesinato, predice que la pena tiene un efecto preventivo, una norma que fomente con ayudas la contratación de discapacitados conseguirá el efecto de que se contraten discapacitados 
pretende realzar la figura del aplicador, en su función co-creadora del derecho.

Sin embargo, nosotros pensamos que la figura del legislador como intérprete merece un estudio específico, como principal mediador entre la comunidad jurídica y el derecho. La acción del legislador tiene su origen y fin principal en la comunidad jurídica y en los ciudadanos que la forman y permite la comunicación social en términos jurídicos. Así las cosas, la labor del legislador es de intérprete del derecho cuya finalidad es extraer los significados de las acciones humanas en sus contextos y reenviarlos al derecho. En este proceso podemos reconocer plenamente una hermenéutica del derecho, cuyas características serían las siguientes:

- El legislador no parte de una situación de ajuridicidad, de ausencia del derecho. El privilegio de la visión del legislador consiste en que puede examinar el fenómeno jurídico, la actividad de las instituciones y el juego de las prácticas sociales desde fuera, sirviéndose del "punto de vista externo" y contestar a la pregunta ¿Cómo funciona? analizando los efectos orientadores de las normas en los diferentes ámbitos.

- Así la tarea del legislador presupone una lectura significativa de la realidad social constitutiva de un círculo hermenéutico. Los portadores de sentido que el legislador interpreta son los múltiples imputs que le llegan de la sociedad civil, evaluaciones formalizadas de las políticas públicas, informes que provienen del aparato del estado, acción de los grupos de presión, dictámenes jurídicos etc... No deben olvidarse las precomprensiones de tipo político e ideológico que, en un sistema parlamentario de partidos como el nuestro, suelen ser las que abren el círculo hermenéutico y, al mismo tiempo, lo pueden convertir en vicioso cuando la interpretación del legislador sólo atiende a aquellos "datos" que confirman la fórmula ideológica de turno. Las lecturas del legislador son lecturas públicas y están sometidas a debate 
$\mathrm{y}$, por lo tanto, es frecuente el conflicto de interpretaciones y en no pocas ocasiones, se ponen en cuestión definiciones esenciales de los grupos sociales o nacionales que participan en el debate político. Toda esta actividad hermenéutica va dirigida a un fin aplicativo: busca innovar el ordenamiento abriendo la tradición jurídica representada en el mismo a nuevos significados.

- La interpretación del legislador es una interpretación jurídica. Toda interpretación de un hacedor de normas supone una referencia al mundo propio de lo jurídico. La visión del legislador busca comprender la relación significativa que existe entre las normas y las prácticas sociales, entretejidas con acciones guiadas por las normas y establecer lo que "no funciona" en ellas. Se trata de examinar la coordinación de las acciones que llevan a cabo las normas existentes y valorar sus efectos, desde la perspectiva aplicativa del "qué se puede hacer". Pero este examen no se limita a una perspectiva práctica, estratégico-instrumental de la coordinación de múltiples acciones. La visión del legislador permite incluir en la interpretación legislativa el punto de vista de la justicia ya que desde su "alejamiento" puede evaluar los efectos de las acciones de los ciudadanos sobre los demás ciudadanos en términos de gratificación o perjuicio mutuo. Pero, lo más relevante, a nuestro entender es que el legislador comprende la realidad con el lenguaje del derecho, para producir derecho. Por así decirlo, el legislador tiene encomendado lo que según "la falacia naturalista" es imposible hacer: extraer normas de lo fáctico. El paso de lo fáctico a lo contrafáctico es posible porque la lectura significativa del legislador se hace incluyendo el lenguaje del derecho: el legislador interpreta la realidad social, traduciéndola a su terminología: actos y efectos jurídicos, negocios jurídicos, derechos, obligaciones, relaciones jurídicas, ejercicio de potestades, validez de las normas y eficacia de los sistemas jurídicos etc y evalúa los efectos de estas estructuras. 
- Por ejemplo, en el caso de los nuevos sistemas transporte eléctrico urbano (patinetes o scooters etc.), el enfoque del creador de normas pasa por la percepción de la necesidad de coordinar el uso de estos nuevos vehículos con la circulación de viandantes y demás vehículos. El "legislador" está en disposición de analizar quién gana y quién pierde de la situación de falta de coordinación: pierden los viandantes y los usuarios de los nuevos vehículos por la situación de riesgo en la que se encuentran y los conductores de vehículos de motor por la inseguridad general que se crea en el tráfico. En términos jurídicos la situación puede definirse de permisividad y la coordinación en términos jurídicos implica el recurso al instrumento jurídico de establecer obligaciones para los diversos implicados que guíen su conducta. (previa definición de los implicados). La definición de los modelos de compromiso (ya establecidos y consolidados en el transporte de vehículos a motor) puede ir desde la prioridad del uso de las nuevas formas de transporte a la prohibición total mediante una ponderación de los (nuevos) criterios ecológicos y de salud (baja contaminación) con los valores tradicionalmente considerados en el transporte urbano: fluidez, rapidez, orden y seguridad. Por último, la acción legislativa no puede ser ajena a los criterios de justicia, es decir, de gratificación o perjuicio derivado del efecto de las acciones de unos agentes sobre otros.

- Parece claro, a estas alturas, que la tarea del legislador no es sencilla. No se trata sólo, como indican Viola y Zaccaria de que la actividad del legislador se haya degradado desde un punto de vista técnico o se haya visto desbordada por una multiplicidad de nuevos fenómenos necesitados de regulación, ni de que las expresiones lingüísticas utilizadas en las normas queden fuera de su control, creando en el texto zonas de oscuridad interpretativa que impidan la "total claridad". El problema principal, es que no es fácil prever cual será el resultado del uso de los concretos 
instrumentos normativos (asignar obligaciones, reconocer derechos, crear o modificar relaciones jurídicas, atribuir potestades...) sobre la materia social y las acciones humanas que la componen a la vista de su inconmensurable variedad e imprevisibilidad. El legislador lo que hace es una predicción: contempla ad futurum una serie de efectos de las normas que promulga (o de las que deroga o modifica) sobre las acciones, prácticas o instituciones que disciplina. Esta predicción se fundamenta en la interpretación previa de la práctica regulada y de su significado, siempre abiertos a discusión y revisión en el debate público. Por ejemplo, bajar impuestos puede tener como objetivo previsto incrementar la recaudación a medio plazo al estimular la actividad económica. Pero esta predicción no puede ser, a nuestro entender, ni siempre precisa (pueden darse múltiples hechos no previstos), ni siempre atinada (puede dar lugar a acciones y prácticas no previstas inicialmente por el legislador). La predicción del legislador presupone que la norma es el instrumento adecuado para solucionar un problema detectado en el debate público, algo que no tiene por qué ser así. Y evidentemente la norma puede producir otros efectos no previstos, como veremos. Esa predicción sería, a nuestro entender, el componente principal de la "ratio legis" o finalidad de la ley, uno de los instrumentos tradicionales de interpretación jurídica. El legislador pierde el control de sus predicciones ya desde el momento en el que la nueva norma se integra en un ordenamiento, junto con otras normas con las que crea relaciones de sentido, si bien, la independencia total de la norma llega, como veremos, al integrarse en las prácticas sociales a las que se refiere.

- Cabe referirnos en este momento a la teoría de Guastini que diferencia entre disposición y norma. Según esta teoría el legislador emite una disposición entendida como texto jurídico normativo, que sólo se convierte en norma después de la 
interpretación del texto por el juez. Como dice Viola y Zaccaria en las teorías hermenéutico-jurídicas el sentido de las disposiciones - que no viene en absoluto disipado como base de partida de la práctica interpretativa- se completa necesariamente en la «concretización»39.Sin embargo, estas teorías, a nuestro entender olvidan que las normas jurídicas van dirigidas no a los jueces, sino a los ciudadanos que en primer término deben aplicarlas, es decir, interpretarlas.

\subsection{EL CIUDADANO COMO INTÉRPRETE PRINCIPAL DEL DERECHO}

El ciudadano es el principal intérprete del derecho porque es el que tiene que guiar sus acciones por las normas. Como dice Viola y Zaccaria:

En el fondo, si el derecho sirve para orientar la vida social, esto es, las elecciones y las decisiones de los ciudadanos y de los funcionarios, no podrá ser comprendida de modo completo sino poniéndose en su punto de vista, en el punto de vista de los que deben decidir cómo actuar, que deben deliberar en torno a ciertos fines, que quieren realizar ciertos objetivos.

Prevalece en este caso el punto de vista interno del derecho. Partimos de una necesidad perentoria: la de saber qué hacer. Este "saber qué hacer" no es construido exclusivamente desde la disposición normativa. Es un saber que integra diversos códigos y conocimientos: tanto morales, como sociales y jurídicos, deseos, intereses etc. El destinatario del derecho siente la necesidad de una comprensión productiva de la norma, es decir, necesita saber qué hacer en las diversas circunstancias y situaciones, aunque este saber qué hacer no esté precisado expresamente. Necesita saberlo no sólo para seguir los dictados de la norma sino también para

39 Viola y Zaccaria, Derecho e Interpretación..., 126 y 127 En la doctrina estructuradora del derecho (Strukturierende Rechtslehre) de Friedrich Müller se radicalizan las tesis hermenéuticas, en.el fondo rebajando el valor de la conexión entre el texto normativo (o la disposición) y la norma; se sostiene en efecto que el autor del texto no crea en realidad normas, ya que el texto no produce de por sí efecto normativo alguno, sino tan sólo "datos de entrada". 
decidir no hacer algo aunque esté permitido o hacer algo aunque esté prohibido y para reconocer y distinguir obligaciones, derechos y autorizaciones de diversa índole en nosotros y en los demás. Denominamos "modelo de compromiso" a este "saber que hacer" estructurado y razonado. Mediante este modelo, sabemos que el matrimonio es bígamo, que tomar drogas es malo, que el periodista tiene que contrastar las noticias para proporcionar información veraz y sacamos las consecuencias pertinentes de estas afirmaciones. Gadamer ejemplifica esta "comprensión productiva" 40 , cuando habla de la comprensión de una orden en su obra Verdad y Método.

Comprender la orden significa aplicarla a la situación concreta a la que se refiere. Es verdad que a veces se hace repetir la orden como manera de controlar que se había entendido bien, pero esto no cambia el hecho de que su verdadero sentido sólo se determina en la concreción de su ejecución «adecuada». Esta es la razón por la que existe también una negativa explícita a la obediencia, lo que no quiere decir simplemente desobediencia, sino que se legítima por el sentido de la orden y la concreción de la misma que queda a cargo de uno. El que se niega a obedecer una orden la ha entendido. Se niega a hacerlo porque es él el que la aplica a la situación concreta, y sabe lo que su obediencia implicaría para ésta. Evidentemente, la comprensión se mide según un patrón que no está contenido ni en la literalidad de la orden ni en la verdadera intención del que la da, sino únicamente en la comprensión de la situación y en la responsabilidad del que obedece. Incluso cuando una orden se da por escrito, o se pide por escrito, con el fin de hacer controlable la corrección de su comprensión y ejecución, tampoco por este procedimiento queda dicho todo. Una forma de picaresca es ejecutar las órdenes de manera que se cumpla su literalidad pero no su sentido. Por eso no hay duda de que el receptor de una orden tiene que comprender a su vez productivamente el sentido de la misma.

40 Gadamer, Verdad y Metodo, 211. 
Una vez sentado esto cabe preguntarse: ¿Cuál es la esencia de este "saber qué hacer" desde la perspectiva del Derecho? El carácter de la orientación de la acción por medio del derecho viene determinado por lo ya dicho ut supra: el destinatario de las normas no considera que cumplirlas sea un fin en sí mismo, sino un medio para conseguir sus propios fines. La moral orienta el comportamiento hacia el bien pero el derecho es un medio y así se percibe. El destinatario de las disposiciones reguladoras "se aprovecha" de ellas: busca, por un lado, potenciar las oportunidades que le abren y, por otro, busca eludir o evitar aquellos aspectos que le sean desventajosos. El legislador predice hasta cierto punto este comportamiento. Así sucede, por ejemplo, cuando una determinada regulación impositiva promueve de forma masiva determinadas inversiones que "desgravan" o cuando las ayudas a la contratación laboral consiguen incrementar las contrataciones de grupos de difícil empleabilidad. Este "aprovechamiento" del derecho es un fenómeno "constitutivo", o "nuclear", en los términos que habla Taylor ya que si hay algo que los ciudadanos consideramos esencial para la vida en sociedad en nuestra cultura es "la protección que dispensa el derecho", entendida por los ciudadanos en términos de "aprovechamiento" de las condiciones establecidas legalmente. Sin embargo, al mismo tiempo, esta dinámica "ventajista", hace que la práctica social cubierta por la norma (con la que forma un conjunto) se independice, por así decirlo, del "proyecto de sentido" diseñado por el legislador, y se imbrique en la creación de "un mundo" propio"41 para desplegar efectos no previstos ni por el legislador en sus predicciones" ni por los destinatarios del derecho en sus modelos de compromiso. Así sucede, cuando la desregulación de las entidades financieras provoca una burbuja inmobiliaria, cuando la ocupación por la fuerza de espacios habitacionales alcanza una protección jurídica que se percibe inmerecida o cuando se permite la conversión del ahorro depositado en cuentas bancarias en acciones preferentes de los propios

41 Nos servimos de las expresiones que utiliza Ricoeur en su teoría de interpretación de textos y acciones 
bancos sin información suficiente, con pérdida masiva de los ahorros. A veces, estas situaciones tienen su origen en la "falta de claridad" de la norma: por ejemplo, cuando no queda claro en qué país se ha de tributar cuando se obtienen rentas en el extranjero ${ }^{42} \mathrm{o}$ cuando determinadas empresas de servicios se aprovechan del uso de plataformas digitales para eludir la aplicación de la normativa laboral a las personas de prestan los servicios (reparto, transporte etc). La práctica social refuerza o debilita el sentido de la norma a través de las consecuencias de su aplicación La dinámica expuesta puede alterar la apuesta de sentido para algunos de los actores o para todos, tanto en favor como en contra de sus intereses. Todo ello sin contar con los supuestos de simple desobediencia, en los que el destinatario decide aprovecharse de las ventajas de no vincularse a la norma.

Esta situación produce el conflicto jurídico en el que se apela al derecho. Esta apelación al derecho puede producirse, básicamente de tres maneras:

- De manera informal, con un arreglo entre los distintos actores

- Reevaluando la fórmula regulatoria en función de los cambios operados en los aspectos sociales, económicos o inmateriales afectados. Esta petición de reevaluación pasaría al ámbito político y legislativo.

- Mediante el recurso a las autoridades aplicativas, básicamente jurisdiccionales.

Así nos acercamos a la zona del conflicto que es en la que se despliega la tarea del aplicador del Derecho. Cuando nos acercamos a la zona de conflicto, es decir, cuando se ponen en cuestión nuestras acciones es cuando aparece la necesidad de dar razón de las mismas, de justificarlas

42 La tributación debe hacerse en el lugar donde se encuentre "el centro de interés". 
a través del derecho43. Esta justificación está presente tanto en nuestras demandas a las autoridades, como en nuestras críticas a los demás, como en nuestra defensa frente a imputaciones o acusaciones. La justificación de nuestras acciones debe asumir la forma narrativa, ya que la forma universal de interpretar la acción humana es "el relato" un relato que se crea por la norma y para la norma: en la expresión que ha hecho fortuna en el lenguaje judicial, "un relato de hechos" un relato cuyo dueño final será el aplicador formal del derecho.

Así, en conclusión, la interpretación del derecho por parte de sus destinatarios oscila entre su consideración como instrumento para la consecución de los propios fines confiando en el amparo que le otorgan las instituciones y su entendimiento como justificación de las propias acciones ante el conflicto.

\subsection{EL APLICADOR DEL DERECHO COMO INTÉRPRETE DEL DERECHO}

Las teorías modernas del derecho tienden a considera la interpretación del derecho por los órganos jurisdiccionales como una tarea de creación del derecho que viene a completar la del legislador (Guastini), no sólo porque es imposible que el legislador prevea todos los posibles supuestos de aplicación y toda la casuística relacionada con la disposición normativa, sino porque, aun cuando el sentido de la norma sea claro, la determinación de esa claridad supone una actuación interpretativa previa. Sin embargo, entre el legislador y el aplicador, el derecho que se lleva hasta la jurisdicción ha pasado por una serie de vicisitudes poco percibidas que son el trasfondo de la labor interpretativa del aplicador. ¿Cuáles son esas vicisitudes?

a) Se considera interpretación jurídica la averiguación del sentido de la norma para su aplicación a un caso concreto. Sin embargo, hay dos circunstancias que pasan desapercibidas en

43 Hart, El concepto de Derecho...,174. 
este simple esquema. La primera es que el caso concreto es un "conflicto" La naturaleza conflictual de la aplicación jurídica determina la interpretación judicial. La segunda es que el aplicador formal tiene que vérselas con los efectos no "predichos" de las disposiciones reguladoras una vez que se integran en el mundo de sus destinatarios. No sólo porque el aprovechamiento de la norma por sus destinatarios ha rebasado las predicciones del legislador, sino también porque es posible que se pida la aplicación del mismo criterio normativo a supuestos similares no contenidos en el proyecto original. El aplicador se encuentra con la dialéctica entre el carácter de resumen del texto normativo y la inconmensurabilidad de situaciones creadas por las acciones humanas. La interpretación del aplicador no puede limitarse, por lo tanto, a la mera "aclaración" del sentido, sino que se encuentra por un lado con la necesidad de adaptar el proyecto de sentido original del legislador a lo concreto y, por otro lado, con la necesidad de superar un conflicto "interpretativo" de una forma que sirva de paradigma para resolver conflictos posteriores de naturaleza similar; es decir, la solución se concibe ya ab initio para “conflictos futuros". Sólo así la labor del juez puede completar la del legislador.

b) El conflicto que llega al aplicador ha generado dos o más relatos que pretenden justificar la aplicación del derecho de una o de otra manera. La justificación tiene su apoyo en un relato construido sobre la norma y en la "justicia” de su pretensión en términos de correspondencia. Por ejemplo, una auxiliar de pisos de un hotel sostiene que ha estado realizando funciones de gobernanta durante el último año y medio y reclama lo que le "corresponde": la diferencia salarial y la consolidación en su persona de la categoría de Gobernanta. Este relato se ha construido mirando a una disposición normativa que establece que "los trabajadores que realicen trabajos correspondientes a un grupo profesional 
superior tendrán derecho a la diferencia salarial entre puestos y a la consolidación”. La otra parte del conflicto llevará otro relato o el mismo siempre con una referencia a una norma jurídica como elemento básico para su construcción. Ambas se servirán del argumento de justicia como correspondencia como elemento “dramático" del relato.

El aplicador del derecho, funcionario o juez recibe el relato de los destinatarios del derecho y mantiene en su comprensión la estructura de "relato". El juez relata las acciones relevantes con vistas a la norma y extrae las normas aplicables a la vista de las acciones relevantes, en un círculo hermenéutico. Sin embargo, para evitar el círculo hermenéutico vicioso al que se refiere Hart44, debe tenerse en cuenta que:

a) Cuando el conflicto llega al juez lo hace en forma de caso. La casuística viene a ocuparse de los innumerables supuestos de acciones a los que puede aplicarse una norma. En la casuística es donde se desarrolla la función del aplicador formal del derecho. A través de la analogía de casos se resuelve el problema de la rigidez y equivocidad de la norma. La analogía es el instrumento fundamental del legislador, pues nunca un caso es exactamente a otro.

b) El juez vuelve a la perspectiva externa del derecho a la que se refiere Hart. Al igual que el legislador su labor es una contestación a la pregunta ¿Cómo funciona?, pero a diferencia del legislador, lo hace limitándose a evaluar unas acciones precisas y concretas. Por lo tanto, el derecho creado con el caso es una reconstrucción del sentido del proyecto original del legislador, con su contenido predictivo incluido, con vistas a hacerlo "funcional" en un caso de conflicto (de relatos diferentes) y a su proyección a conflictos de similar naturaleza. Este hacer "funcional" es el contenido de lo que debemos entender en

44 Hart, El concepto de Derecho..., 161: cita en nota 28. 
términos hermenéuticos como el principio de legalidad: lo legal es hacer que las disposiciones normativas funcionen en un caso concreto de acuerdo con el proyecto de sentido definido por el legislador.

Así las cosas, la función del aplicador del derecho es examinar y entender el proyecto de sentido que proviene del legislador, examinar cómo ha cobrado vida propia en las diversas justificaciones que se le presentan y reconstruirlo en el caso concreto a fin de trasladarlo como modelo futuro para resolver conflictos similares. El juzgador tiene acceso a los efectos de las diversas acciones y debe tener en cuenta su ajuste a las "predicciones" del legislador Por lo tanto puede enjuiciar con criterios de justica, en función de lo que "corresponde". Si estas finalidades no se alcanzan la tarea de aplicación del derecho como reveladora de significado habrá fracasado.

Estas aproximaciones a la interpretación no agotan todas las posibilidades de una hermenéutica del derecho como co-relación entre acción y texto regulador. Baste como acercamiento a las posibilidades abiertas por la hermenéutica filosófica en la búsqueda del sentido dentro del ámbito de las ciencias humanas.

\section{REFERENCIAS BIBLIOGRÁFICAS}

Berlin, Isaiah. El sentido de la realidad, sobre las ideas y su Historia. Madrid: Taurus, 1998.

Beuchot, Mauricio. "Breve exposición de la hermenéutica analógica”. Revista Teología 45 (2008): 491-502.

Curco Cobos, Felipe. “¿Fue Richard Rorty un positivista jurídico? (A Propósito de la Oxford Amnesty Rorty's Lecture de 1993)”. Isonomía [online]. 35 (2011): 119-141. Consultado el 24 de marzo de 2019, http://www.scielo.org.mx/scielo.php?script=sci_arttext\&pid=S140 5-02182011000200004\&lng=es\&nrm=iso. 
Gadamer, Hans-Georg. Verdad y Metodo. Fundamentos de la Hermenéutica filosófica. Salamanca: Ediciones Sigueme, 1993.

García Amado, Juan Antonio. "Filosofía hermenéutica y derecho". Azafea. Revista de filosofía 5 (2003): 191-211.

Grondin, Jean. ¿Qué es la hermenéutica? Barcelona: Herder. Editorial, 2008.

Hart. Herbert L.A. El concepto de Derecho. Buenos Aires: Abeledo Perrot 2009.

Heidegger, Martin. Ser y tiempo. Traducción, prólogo y notas de Jorge Eduardo Rivera C. Santiago de Chile: Editorial Universitaria, 1997.

Kaufmann, Arthur. "Entre iusnaturalismo y positivismo hacia la hermenéutica jurídica”. Anales de la Cátedra Francisco Suárez 50 (2016): 133-142.

Kelsen, Hans. Teoría pura del Derecho. Buenos Aries: Eudeba, 2009.

Muñoz, Francisco y Mercedes García, Derecho Penal. Parte General, $6^{\text {a }}$ ed. Valencia: Tirant lo Blanch, 2004.

Rorty. Richard. Consequences of Pragmatism (Essays: 1972-1980). Minneapolis: University of Minnesota Press 1982.

John R. Searle, “What is an institution?”, Journal of Institutional Economics 1 (2005): 1-22.

Taylor, Charles. Philosophical Papers II Philosophy and Human Sciences. Cambridge: Cambrige University Press 1985.

Thouard, Denis. "Hermeneutique contemporaine, comprendre, interpréter, connaître, Preface (1965)". En George Gadamer, Verité et Methode. Les grandes lignes d'une herméneutique philosophique. Paris: J. Vrin 2011.

Viola, Francesco y Giuseppe Zaccaria, Derecho e Interpretación. Elementos de teoría hermenéutica del Derecho. Madrid: Dickinson, 2007. 
Walzer, Michael. Thick and Thin. Moral arguments and Abroad (Indiana, University of Notre Dame Press, 1999

Ángel Cubo Mayo

Inspección de Trabajo de Cataluña Direcció General de la Inspecció de Treball

Av. del Cardenal Vidal i Barraquer, 20 43005 Tarragona (España) angel.cubo@gencat.cat https://orcid.org/0000-0003-2334-8707 